\title{
TRANSMYOCARDIAL LASER REVASCULARIZATION: OPERATIVE TECHNIOUES AND CLINICAL RESULTS AT TWO YEARS
}

Keith A. Horvath, MD, ${ }^{a}$

Finn Mannting, MD, PhD $^{\mathrm{b}}$

Nancy Cummings, RN ${ }^{\mathrm{a}}$

Stanton K. Shernan, $\mathrm{MD}^{\mathrm{c}}$

Lawrence H. Cohn, $\mathrm{MD}^{\mathrm{a}}$
Objectives: A new technique, transmyocardial laser revascularization, provides direct perfusion of ischemic myocardium via laser-created transmural channels. From 1993 to 1995, we have treated 20 patients (mean age 61 years, four women and 16 men) with transmyocardial laser revascularization. Preoperatively, the average angina class was 3.7 . The patients were screened before the operation by a technetium sestamibi perfusion scan to identify the location and extent of their reversible ischemia. Methods: Operative exposure is gained via a left anterior thoracotomy. With the use of a 850-watt carbon dioxide laser, an average of $21 \pm 4$ channels were created in 22 minutes with a total operative time of less than 2 hours. Results: The in-hospital mortality was two of 20 patients. Three additional patients died after discharge. After an accumulated 172 patient-months (mean follow-up $11 \pm 8$ months, range 1 to 26 months), the mean angina class is $I(p=0.01$ ). Postoperative sestamibi scans were obtained at 3,6 , and 12 months. Using the septum as a control and comparing the postoperative results with the preoperative baseline, we noted a significant improvement in perfusion particularly in the areas of reversible ischemia. Conclusion: These early results indicate that transmyocardial laser revascularization is a simple operative technique that may improve myocardial perfusion and provide angina relief for patients in whom standard methods of revascularization is contraindicated. (J Thorac Cardiovasc Surg 1996;111:1047-53)
$T^{\text {he }}$ he purpose in treating ischemic heart disease is the improvement of blood flow to underperfused myocardium. The mainstays of this treatment are coronary artery bypass grafting (CABG) and percutaneous transluminal coronary angioplasty (PTCA). Even with the success of these interventions, many patients with disabling angina are not candidates for these procedures because of diffuse end-stage coronary vascular disease. Indirect methods of myocardial revascularization have been tried, such as

From the Departments of Cardiac Surgery, ${ }^{a}$ Nuclear Medicine, ${ }^{b}$ and Anesthesiology, ${ }^{\mathrm{C}}$ Brigham and Women's Hospital, Harvard Medical School, Boșton, Mass.

Read at the Twenty-first Annual Meeting of The Western Thoracic Surgical Association, Coeur d'Alene, Idaho, June 21-24, 1995

Received for publication June 21, 1995; revisions requested Oct. 24, 1995; revisions received Nov. 20, 1995; accepted for publication Dec. 26, 1995.

Address for reprints: Lawrence H. Cohn, MD, Department of Cardiac Surgery, Brigham and Women's Hospital, 75 Francis St., Boston, MA 02115.

Copyright $(\mathcal{C} 1996$ by Mosby-Year Book, Inc.

$0022-5223 / 96 \$ 5.00+0 \quad \mathbf{1 2 / 6 / 7 1 4 5 3}$
Beck's poudrage and omentopexy, ${ }^{1}$ Vineberg's thoracic artery implantation, ${ }^{2}$ and Sen's myocardial acupuncture. ${ }^{3,4}$ These techniques provided some benefit but were eventually replaced by CABG and PTCA. The basis of these early methods is neovascularization of the ischemic myocardium. Mirohseini and associates $^{5-9}$ proposed the use of a laser to create transmyocardial channels to provide direct perfusion of the myocardium with ventricular blood. They combined this transmyocardial laser revascularization with CABG and achieved promising results.

After initial experimental work in our laboratory, which demonstrated improved regional contractility and patent channels 30 days after laser treatment of an acute infarct, ${ }^{10,11}$ we began a clinical study of transmyocardial laser revascularization. We report the initial clinical results of using laser revascularization as sole therapy for patients with severe angina untreatable by conventional methods.

\section{Patients and methods}

Between March 1993 and April 1995, 20 patients were treated with transmyocardial laser revascularization at the Brigham and Women's Hospital, Boston. The inclusion 

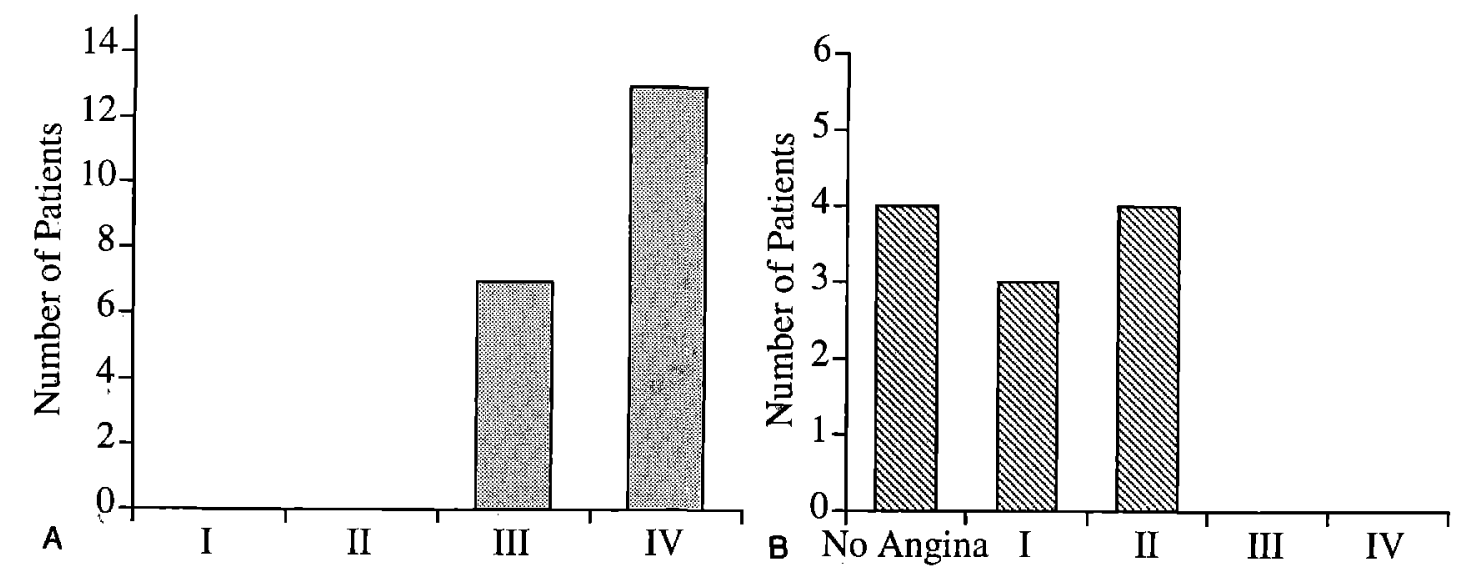

Fig. 1. A, Preoperative Canadian Angina Class in 20 patients. B, Postoperative Canadian Angina Class in 11 patients with at least 3 months' follow-up.

Table I. Angina class, admissions, and nitroglycerin use

\begin{tabular}{|c|c|c|c|c|c|}
\hline & \multirow{2}{*}{$\begin{array}{l}\text { Preoperative } \\
\left(n=16^{*}\right)\end{array}$} & \multicolumn{2}{|c|}{$\begin{array}{l}\text { Postoperative } \\
\quad(3-12 \mathrm{mo})\end{array}$} & \multicolumn{2}{|c|}{$\begin{array}{c}\text { Postoperative } \\
(13-26 \mathrm{mo})\end{array}$} \\
\hline & & $n=11$ & $p^{\dagger}$ & $n=8$ & $p \dagger$ \\
\hline Angina class & $3.7 \pm 0.5$ & $1 \pm 0.9$ & 0.01 & $1 \pm 0.9$ & 0.01 \\
\hline Admissions & $28 \ddagger$ & 4 & 0.001 & 4 & \\
\hline TNG/week & $8 \pm 4$ & $1 \pm 1$ & 0.001 & $1 \pm 0.8$ & 0.001 \\
\hline
\end{tabular}

All values are expressed as the mean \pm standard deviation. $T N G$, Sublingual nitroglycerin.

${ }^{*}$ Excludes the four deaths which have no follow-up.

ip versus preoperative value.

$\Varangle$ Number of admissions for angina in the 12 months before transmyocardial laser revascularization.

criteria for acceptance into this study were threefold: (1) The patients had severe angina refractory to maximal medical therapy; (2) they had reversible myocardial ischemia as documented by a technetium $99 \mathrm{~m}\left({ }^{99_{\mathrm{m}} \mathrm{Tc}} \mathrm{T}\right)$ sestamibi perfusion scan; (3) they were not candidates for PTCA, CABG, or heart transplantation. ${ }^{12}$ The reasons for the inability to undergo PTCA or CABG included severe diffuse disease, inadequate distal targets, and lack of a conduit. If the patient had depressed ventricular function and was a candidate for transplantation, he or she was not enrolled for transmyocardial laser revascularization.

The study was approved by the institutional review board at the Brigham and Women's Hospital. Informed consent was obtained from each patient enrolled.

Of the 20 patients, four $(25 \%)$ were women. The average age was $61 \pm 10$ years (mean \pm standard deviation) with an age range of 47 to 79 years. Ten of the patients $(50 \%)$ had diabetes. The average cholesterol level on admission was $233 \mathrm{mg} / \mathrm{dl}$. On average, the patients had had one previous myocardial infarction. All had severe three-vessel coronary artery disease and all had already undergone previous revascularization procedures. Eighteen $(90 \%)$ had had at least one previous CABG and six $(30 \%)$ of these had already had a second CABG. An average of five vessels had been bypassed with a range of two to ten grafts per patient. PTCA was done in two $(10 \%)$ of the patients. Their average left ventricular ejection fraction was $45 \% \pm 10 \%$ (range $25 \%$ to $70 \%$ ). The distribution of patients according to preoperative angina class is depicted in Fig. $1, A$. The average Canadian Angina Class and number of hospital admissions for angina in the year before transmyocardial laser revascularization are listed in Table I.

All of the patients were receiving multiple medications to control their angina. Preoperatively, seven (35\%) were being treated with intravenous heparin and five of these patients were also receiving intravenous nitroglycerin. Nineteen (95\%) were receiving $\beta$-blockers, $17(85 \%)$ were receiving calcium channel blockers, and $16(80 \%)$ were being treated with long-acting nitrates. All of the patients were taking sublingual nitroglycerin for exacerbations of their angina, averaging approximately six to eight tablets per week.

All of the patients underwent rest and stress ${ }^{99 m} \mathrm{Tc}$ sestamibi scanning before the operation to assess the extent and reversibility of their myocardial ischemia. When able, the patients were stressed by exercise; otherwise, they received dipyridamole (Persantine) at a rate of $0.56 \mathrm{mg} / \mathrm{kg}$ per minute over 4 minutes by intravenous infusion.

Operative technique. The status of all patients was monitored during and after the operation with an arterial line and a pulmonary artery catheter. A thoracic epidural block was placed when possible to provide postoperative 
pain relief. The patients were intubated with a doublelumen endotracheal tube, and a transesophageal echocardiography (TEE) probe was inserted. A baseline TEE study was performed to evaluate the global ventricular function, as well as to determine areas of regional wall motion abnormalities and valvular disease. The patients were positioned in a 45-degree lateral decubitus position and underwent a left anterolateral thoracotomy through the fifth or sixth intercostal space depending on the location of the point of maximal impulse. The pericardium was entered anterior to the phrenic nerve and the heart was suspended in a pericardial cradle. Care was taken to avoid the previous CABGs. As determined by the patient's preoperative ${ }^{99 \mathrm{~m}} \mathrm{Tc}$ sestamibi scan, the area of reversible ischemia was exposed. It was this area that was then treated with the laser.

Laser technology. The laser was a 1000 -watt carbon dioxide device that delivered 850 watts of peak power to the tissue. The maximum output was 80 joules and the pulse width could be varied from 1 to $99 \mathrm{msec}$. The operative settings were a pulse energy of 36 joules and a pulse width of $45 \mathrm{msec}$. The carbon dioxide laser was aimed with helium-neon laser guidance, placed against the epicardium, and fired. The laser was triggered to fire on the $r$ wave of the electrocardiographic cycle when the ventricle was maximally distended and electrically quiescent. The laser energy was absorbed by the blood in the ventricle, and this produced an acoustic image analogous to steam, which was readily visible by TEE in the long-axis four-chamber view. This vaporized tissue and blood denoted transmyocardial penetration. Only shots verified by TEE were considered to have traversed the myocardium. The channels were $1 \mathrm{~mm}$ in diameter and were arrayed in a distribution of one per square centimeter. Bleeding from the channels was controlled with direct finger pressure or an epicardial suture if the pressure was not adequate. Epicardial suturing was required for less than $1 \%$ of the holes drilled.

Follow-up. The patients returned 3, 6, 12, and 24 months after the operation for repeated ${ }^{99 \mathrm{~m}} \mathrm{Tc}$ sestamibi scans. The follow-up scans for each patient were conducted in the same fashion as the preoperative study. The scans were analyzed and scored by two observers in a blinded fashion. The nuclear medicine results were based on counting the number of segments with fixed ischemia and the number of segments with reversible ischemia as viewed on the short-axis scans of the left ventricle. The follow-up studies were compared with the preoperative baseline scans and the change in the number of involved segments was calculated. A difference of two segments or more was considered significant. The septum was not treated by transmyocardial laser revascularization in any of the cases and thereby served as a control to which the treated left ventricular free wall was compared.

The patients were examined at the aforementioned intervals, and they answered a standardized questionnaire designed to assess angina class, activity level, medications, and hospitalizations since the procedure. An unpaired Student's $t$ test was used to compare the results. Differences were considered significant at $p<0.05$. Unless otherwise indicated, results are expressed as mean \pm standard deviation.
Table II. Operative statistics

\begin{tabular}{lc}
\hline Channels & $21 \pm 4$ \\
Energy (joule) & 36 \\
Pulse width (msec) & 45 \\
Operative time (min) & $118 \pm 18$ \\
Lasering time (min) & $22 \pm 6$ \\
EBL (ml) & $150 \pm 50$ \\
\hline
\end{tabular}

$\overline{\text { All values expressed as mean } \pm \text { standard deviation. } E B L}$, Estimated blood loss.

\section{Results}

The operative statistics are listed in Table II. The morbidity of the procedure was minimal. No reoperations for bleeding, wound infections, pneumothoraces, or transfusions were required. No laserinduced arrhythmias developed, and only one patient had postoperative atrial fibrillation. Ten of the patients were extubated in the operating room and the remainder were extubated in the first 36 to 48 hours after the operation. The average stay in the intensive care unit was $2 \pm 1$ days. The average hospital stay was $8 \pm 3$ days. The patients were restarted on their preoperative medications, and these were adjusted as needed in the postoperative period.

Four deaths $(20 \%)$ occurred within 30 days of the procedure. Two patients died in the first 48 hours after the operation, one of a septal infarction that was evolving at the time of the operation (as determined by infarct age at autopsy) and the other of an epidural overdose. Two patients died after discharge. One died on postoperative day 12 (2 days after discharge) of a presumed arrhythmia (autopsy revealed no other obvious cause of death). The other died on postoperative day 18 (11 days after discharge) of bleeding in the upper gastrointestinal tract and pneumonia (as confirmed by autopsy). The lone late death occurred in a patient who died 6 months after the operation in a house fire.

The remaining 15 patients have been followed up for $11 \pm 8$ months (range 1 to 26 months) with an accumulated 172 patient-months of follow-up. The average Canadian Angina Class, angina-related hospital admissions, and nitroglycerin use are listed in Table I. These results are divided into early results (3 to 12 months postoperatively) and late results (12 to 26 months postoperatively). The distribution of patients according to postoperative angina class is depicted in Fig. 1, $B$.

No patient has required increased dosages or types of medications from preoperative levels or regimens. 

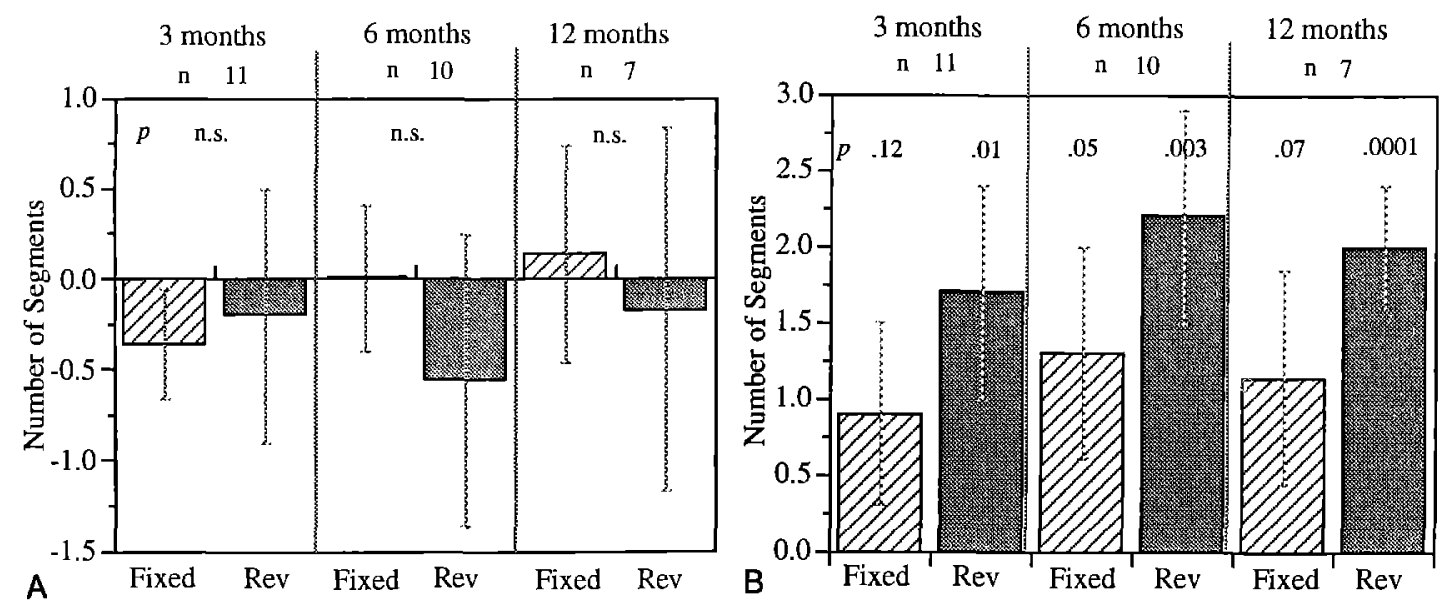

Fig. 2. A, ${ }^{99 \mathrm{~m}} \mathrm{Tc}$ sestamibi scan results of the septum. The septum was untreated by the laser and thereby served as a control. There is no evidence for improved perfusion in either the fixed or reversible segments with time. Fixed, Fixed segments (decreased perfusion at rest and stress); Rev, reversible segments (decreased with stress); $p$ value versus preoperative baseline scan. B, ${ }^{99 \mathrm{~m}} \mathrm{Tc}$ sestamibi scan results of the left ventricular free wall. The laser-treated left ventricular free wall shows improved perfusion in both the fixed and reversible segments with time. Fixed, Fixed segments (decreased perfusion at rest and stress); Rev, reversible segments (decreased with stress); $p$ value versus preoperative baseline scan.

The myocardial perfusion scan results are depicted in Fig. 2, $A$ and $B$. In Fig. 2, $A$, the changes in both fixed and reversible areas of ischemia in the septum are charted. Over time there was no significant change in the number of septal segments with either fixed or reversible abnormalities. Inasmuch as the septum was not treated by the laser, these areas serve as a control and are contrasted with the changes seen in the laser-treated left ventricular free wall (Fig. 2, B). There is a significant improvement in the areas of reversible ischemia with time when compared with the preoperative baseline scans. This improvement approaches significance in the fixed segments as well, but at best it attains a $p$ value of 0.05 at the 6 -month interval. All of the treated areas, both the fixed and reversible segments, showed improved perfusion when compared with the septum.

\section{Discussion}

A review of comparative anatomy demonstrates that myocardial perfusion in reptiles is primarily via blood from the ventricle through transmural channels. Hence the reference to Sen's operation as the "snake heart" procedure. ${ }^{3,4}$ Wearn and associates ${ }^{13}$ described similar channels in the human heart that allowed direct perfusion of the myocardium. Attempts to mechanically create these channels with the use of needles, tubes, and tunnels yielded vary- ing results. ${ }^{14-19}$ Mirohseini and associates ${ }^{5,6}$ pioneered the use of a laser to replicate the reptilian anatomy in a series of patients in the early 1980s. They achieved symptomatic relief and improved perfusion with a lower-power carbon dioxide laser used in conjunction with CABG. Because these patients underwent a combined laser/CABG procedure, evaluation of the results and the contribution of transmyocardial laser revascularization to these results is difficult.

In an effort to investigate the efficacy of transmyocardial laser revascularization, we initially performed a series of experiments in a large animal model of acute myocardial infarction. ${ }^{10,11}$ The results from these experiments indicated that the procedure provided recovery of contractility in the infarct area at 3 hours and at 30 days. Histologic study of the channels at these times demonstrated evidence of patency, minimal thermal damage, and viability of the surrounding myocardium. Using these experimental data as scientific background, we began a clinical study of transmyocardial laser revascularization as sole therapy for severe angina.

Subjectively, the patients' symptoms improved immediately after the procedure and continued to improve during the follow-up period. Related to these findings is the decreased medication use, including diminished nitroglycerin intake. Although the placebo effect may influence the results of 
transmyocardial laser revascularization early on, this effect is unlikely to last for 1 or 2 years.

Objectively, the patients have shown improved perfusion in the treated areas. These improvements are most apparent between 3 and 6 months and have persisted after 1 and 2 years. The patients' septal scan results, shown in Fig. 2, $A$, did not significantly improve with time, but the laser-treated left ventricular free wall did show increased perfusion with time (Fig. 2, B). Similar results have also been observed by Frazier and associates ${ }^{20}$ at the 3 - and 6-month intervals. In addition to symptomatic improvement, the group at the Texas Heart Institute has demonstrated improved perfusion with positron emission tomographic scanning. ${ }^{20}$

The exact mechanism by which transmyocardial laser revascularization may improve perfusion and thereby provide angina relief is unknown. Theoretically, the channels provide a passage for blood to flow from the ventricle into the myocardium, where it may diffuse into the interstitium or be further transported by blood vessels intersecting the channels. A pressure gradient across the myocardium would encourage this flow. ${ }^{8,21-23}$ With time, the channels may become endothelialized. ${ }^{8}$ The presence of these channels and the energy delivered by the laser to the myocardium may stimulate angiogenesis, which would further improve perfusion via collateral formation. If so, angiogenesis may be supplemented by seeding the channels with angiogenic growth factors. ${ }^{24,25}$ Further experimental work is planned to investigate the mechanism of transmyocardial laser revascularization.

Clinically, transmyocardial laser revascularization may also be useful in treating transplant recipients, whose diffuse atherosclerosis is due to chronic rejection, ${ }^{26-28}$ which makes standard grafting untenable. The largest use for transmyocardial laser revascularization will be in conjunction with $\mathrm{CABG}$ for patients in whom standard bypass grafting cannot be adequately accomplished in all territories because of the lack of distal targets or the lack of a conduit. First, however, we are planning to begin a randomized controlled trial of transmyocardial laser revascularization alone to be compared with medical therapy for angina.

In conclusion, our results at 2 years indicate that use of transmyocardial laser revascularization may relieve angina, improve perfusion, and decrease hospital admissions in a cohort of patients who are otherwise untreatable by conventional revascularization.

\section{REFERENCES}

1. Beck CS. The development of a new blood supply to the heart by operation. Ann Surg 1935;102:801-13.

2. Vineberg A. Clinical and experimental studies in the treatment of coronary artery insufficiency by internal mammary artery implant. J Int Coll Surg 1954;22:503-18.

3. Sen PK, Udwadia TE, Kinare SG, Parulkar GB. Transmyocardial acupuncture, a new approach to myocardial revascularization. J Thorac Cardiovasc Surg 1965;50:181-9.

4. Sen PK, Daulatram J, Kinare SG, Udwadia TE, Parulkar GB. Further studies in multiple transmyocardial acupuncture as a method of myocardial revascularization. Surgery 1968;64: 861-70.

5. Mirohseini M, Muckerheide M, Cayton MM. Transventricular revascularization by laser. Lasers Surg Med 1982;2:18798.

6. Mirohseini M, Fisher JC, Cayton MM. Myocardial revascularization by laser. Lasers Surg Med 1983;3:241-5.

7. Mirohseini M, Cayton MM, Shelgikar S, Fisher JC. Clinical report: laser myocardial revascularization. Lasers Surg Med 1986;6:459-61.

8. Mirohseini M, Sheligikar S, Cayton MM. New concepts in revascularization of the myocardium. Ann Thorac Surg 1988; 45:415-20.

9. Mirohseini M, Sheligikar S, Cayton MM. Transmyocardial laser revascularization, a review. J Clin Laser Med Surg 1993;11:15-9.

10. Horvath KA, Smith WJ, Laurence RG, Byrne JG, Schoen FJ, Cohn LH. Improved short- and long-term recovery after an acute myocardial infarct treated by transmyocardial laser revascularization. Surg Forum 1993;44:220-2.

11. Horvath KA, Smith WJ, Laurence RG, Schoen FJ, Appieyard RF, Cohn LH. Recovery and viability of an acute myocardial infarct after transmyocardial laser revascularization. J Am Coll Cardiol 1995;25:158-63.

12. Berman DS, Kiat H, Maddai J. The new Tc $99 \mathrm{~m}$ myocardial perfusion imaging agents: Tc $99 \mathrm{~m}$-Sestamibi and Tc $99 \mathrm{~m}-$ Teboroxime. Circulation 1991;84(Suppl):I7-21.

13. Wearn JT, Mettier SR, Klumpp TG, Zschiesche LJ. The nature of the vascular communications between the coronary arteries and the chambers of the heart. Am Heart J 1933;9: 143-64.

14. Khazei AH, Kime WP, Papảdopoulos C, Cowley RA. Myocardial canalization, a new method of myocardial revascularization. Ann Thorac Surg 1968;6:163-71.

15. Kuzela L, Miller GE. Experimental evaluation of direct transventricular revascularization. J Thorac Cardiovasc Surg 1969;57:770-3.

16. Anabtawi IN, Reigler HT, Ellison RG. Experimental evaluation of myocardial tunnelization as a method of myocardial revascularization. J Thorac Cardiovasc Surg 1969;58:638-46.

17. Walter P, Hundeshagen H, Borst HG. Treatment of acute myocardial infarction by transmural blood supply from the ventricular cavity. Eur Surg Res 1971;3:130-8.

18. Munro J, Allen R. The possibility of myocardial revascularization by creation of a left ventriculocoronary arterial fistula. J Thorac Cardiovasc Surg 1969;58:25-32.

19. Pifarré R, Jasuja ML, Lynch RD, Neville WE. Myocardial revascularization by transmyocardial acupuncture. J Thorac Cardiovasc Surg 1969;58:424-31.

20. Frazier OH, Cooley DA, Kadipasaoglu KA, et al. Transmyo- 
cardial laser revascularization: initial clinical results. Circulation 1995;90(Suppl):I640.

21. Okada M, Shimizu K, Horii H, Nakamura K. A new method of myocardial revascularization by laser. $\mathrm{J}$ Thorac Cardiovasc Surg 1991;39:1-4.

22. Nematzadeh D, Rose JC, Shryvert T, Huang HK, Kot PA. Analysis of methodology for measurement of intramyocardial pressure. Basic Res Cardiol 1990;85:105-19.

23. Downey JM, Kirk ES. Distribution of the coronary blood flow across the canine heart wall during systole. Circ Res 1974;34:251-7.

24. Folkman J, Klagsburn M. Angiogenic factors. Science 1987; 235:442-7.

25. Hockel M, Schlenger K, Doctrow S, Kissel T, Vaupel P. Therapeutic angogenesis. Arch Surg 1993;128:423-9.

26. Fyfe AI. Transplant athetosclerosis: the clinical syndrome, pathogenesis and possible model of spontaneous atherosclerosis. Can J Cardiol 1992;8:509-19.

27. Eich DM, Johnson DE, Hastillo A, et al. Accelerated coronary atherosclerosis in cardiac transplantation. Cardiovasc Clin 1990;20:199-211.

28. Adams DH, Wyner LR, Karnovsky MJ. Experimental graft arteriosclerosis: immunocytochemical analysis of lesion development. Transplantation 1993;56:794-9.

\section{Discussion}

Dr. Reinold Jones (San Francisco, Calif.). Dr. Horvath and his associates have accurately portrayed the laser technology, patient selection, and surgical techniques in the performance of transmyocardial laser revascularization. Their group is to be complimented on their excellent results.

Phase I of the Food and Drug Administration (FDA) clinical trial was started in January 1990 with Dr. John Crew as the principal investigator. In phase I we were permitted 15 patients. The first patient is still alive at 87 years of age with no angina.

In our early experience the only assurance of a patent laser channel into the left ventricle was by subjective observation of a spurt of blood after the laser strike. In the sixth case, we implemented the use of TEE, which visualizes a jet of bubbles when the laser energy strikes blood in the left ventricle. Only positive shots by TEE are considered as completed channels. These bubbles are not steam but elemental gases produced by photomolecular disruption from carbon dioxide laser energy. Using transcranial Doppler ultrasonography, we hear the bubbles reaching the middle cerebral artery in small amounts without neruologic sequelae.

At the San Francisco Heart Institute Dr. Crew and I have now operated on 28 patients with no operative mortality. We have had three late deaths; one patient died 3 months after the operation, angina-free, of a preexisting arrhythmia, one died 9 months after the operation of pulmonary disease, and one died at 29 months of a suspected myocardial infarction.

In our series, Dr. Crew and I operated on only one patient who had no previous surgery, and she had vessels too small to bypass. Thirty-two months after the operation she has limited angina but is still working full time.

We are now using our third prototype laser with modifications suggested by our initial experience in the phase I study of 15 patients. Nine centers are currently performing this procedure under FDA control and guidelines.

We wish to acknowledge the research and clinical work of Dr. Mirhoseini and his unfailing faith in this controversial procedure.

The animal studies of Drs. Horvath and Cohn have demonstrated the validity of our clinical impressions. Drs. Cooley and Frazier have added further proof of revascularization with preoperative and postoperative positron emission tomographic scans demonstrating increased metabolism invisible on initial thallium studies.

I would like to ask a few questions: First, why does the thallium take so long to respond ( 3 to 6 months) when clinical success is so rapid?

Dr. Horvath. That is a good question. When we designed this study we thought that it was going be difficult to identify when to start using scans to remeasure perfusion. We were more interested in the long-term follow-up than in the immediate effects. Therefore, we picked 3 months arbitrarily as the first postoperative visit. We did, out of curiosity, obtain a few scans on some of the patients before their discharge and saw some improvement. That improvement seems to continue into the 6-month period, probably related to the fact that the laser channels tap into already existing collaterals and allow those collaterals to further develop. Some have even speculated that the laser energy itself allows for angiogenesis to occur and that is why perfusion continues to improve.

Dr. Jones. Do you foresee the use of transmyocardial revascularization in patients with acute ischemia?

Dr. Horvath. Our laboratory work was done in an acute ischemia model and we saw some striking results with that. The laser was able to salvage sheep that had acute infarcts. There may be an application for that, but as it stands the best use is going to be in the setting of chronic ischemia, again with an ability to tap into the already existing collaterals.

Dr. Jones. Do you foresee the use of transmyocardial revascularization in high-risk patients such as Jehovah's Witnesses? Dr. Crew attempted four video-assisted thoracoscopic transmyocardial revascularizations in Saudi Arabia with Dr. Raffa in November of 1994 on patients with no prior surgery. If transmyocardial revascularization is successfully proven to be valid and lasting, do you think this may be an initial viable alternative?

Dr. Horvath. First we have to decide whether it is an alternative to bypass. However, in patients who have those types of restrictions, I think it is safe as far as blood loss is concerned and in fact may be a better alternative.

Dr. D. Craig Miller (Stanford, Calif.). It has been controversial whether the microchannels actually remain open on the endocardial surface. Can you elaborate on your autopsy data?

Dr. Horvath. We have seen on autopsy that the channels are open. The channels appear to close near the epicardial surface approximately 100 to $300 \mu \mathrm{m}$ from the surface on cross section. The most difficult part is to identify all of the channels at autopsy, especially with time and the natural healing process. It is very difficult to say that something is a channel versus a preexisting vessel, and that has been the limitation. 
Dr. Ed Verrier (Seattle, Wash.). This same presentation was informally done by Larry Cohn before the Cardiac Surgery Biology Club a few months ago. It generated significant discussion and also engendered a review of the physiologic literature. It is safe to say that no physiologic study has shown either that the channels stay open or that there is subendocardial flow through the chamber into the functioning subendocardial muscle. You have presented clinical data that there may be a beneficial effect of using this procedure in the ischemic patient. There is also clear evidence that the condition of many patients with chronic angina will improve with medical therapy without this type of intervention. I believe that the controversy remains about justification for this expensive equipment without physiologic justification to benefit only a few patients. We need more information about how this works, particularly physiologic experimental information, because otherwise it resembles a Vineberg-type approach.

Dr. Horvath. Transmyocardial laser revascularization has been called a "high-tech Vineberg." However, you have to remember that the Vineberg operation worked, and we have angiographic and metabolic data that show that there was perfusion via those types of grafts. I also agree that a large amount of work needs to be done to ascertain the mechanism-whether there is a short-term benefit from the channel itself carrying blood flow or whether there is a more long-term benefit that results merely from delivering laser energy to the heart. The analogy that I have seen historically is the paper on ligation of the internal thoracic artery by Diamond's group in the early $1960 \mathrm{~s}$. They show that the patients subjectively improved as a result of ligation of the thoracic artery; however, that improvement did not continue beyond 7 months. We have results that show subjective improvement at the 2-year interval, and we also have some objective proof of improved perfusion based on the nuclear medicine scans. There appears to be something working other than just "smoke and mirrors."

Dr. John Benfield (Sacramento, Calif.). The history of myocardial revascularization is fascinating. It goes back at least to Claude Beck at the Cleveland Clinic putting talc in the pericardium to improve myocardial revascularization. Then there were the Glover procedure (internal thoracic artery ligation) and the Vineberg procedure (internal thoracic artery implantation). Now we have this procedure. Fortunately, scientific evaluation is underway. Before this procedure becomes widely used, however, I wish to hear from you where and how and by whom and under what circumstances this procedure should be further tested. Presumably you do have institutional review board permission to do this. What needs to happen now to keep this procedure from being used prematurely in centers where it perhaps should not be tried?

Dr. Horvath. First we need to perform more experimental work to develop the mechanism. On the clinical front, using it as sole therapy in patients for whom no other treatment is available is acceptable. That probably needs to continue and the follow-up needs to be continued as well. At this point combining transmyocardial revascularization with bypass is dangerous because it is difficult to determine whether the benefit is due to the bypass or to the laser. The best study that we can do now is the new FDA protocol to compare transmyocardial laser revascularization with medical therapy after randomization in patients with end-stage coronary vascular disease. The results of this study will help to validate the procedure.

Dr. Benfield. Perhaps my question was not entirely clear. Let's assume for a moment that I'm a very active and highly thought of cardiac surgeon in a very good community hospital where my group and I might be doing 600 successful bypass procedures a year. Should I consider undertaking this procedure as part of my practice? If so, why? If not, why not? If not, what steps would need to be taken before I should consider undertaking this procedure in my practice?

Dr. Horvath. I think you should undertake it for patients for whom there are no other options. I do not think you should present it to patients as an alternative to standard well-respected well-studied methods of revascularization such as bypass surgery.

Dr. Miller. What are the FDA's prerequisites to enter the phase III trial?

Dr. Horvath. It has been hard to pin down what the FDA wants in the phase III trial. They want us to use the same criteria that we have used for entering patients into this sole therapy group.

Dr. Miller. What institutions are going to be allowed to join your bandwagon?

Dr. Horvath. The FDA has limited the institutions to those currently included in the study, that is, the nine in the United States that are performing the procedure.

Dr. George E. Miller (Pebble Beach, Calif.). In the mid-1960s, we and many other investigators attempted to show patency of transmyocardial channels connecting the left ventricle with the myocardial sinusoids in the experimental laboratory. These channels were produced by using large-bore cutting needles and extracting cores of myocardium from the left ventricle through to the epicardium, then closing the epicardium. We were never able to demonstrate the late presence of patent channels. Why would channels produced by laser remain open whereas those produced by steel scar over?

Dr. Horvath. We have done that in the laboratory as well, as have other investigators. Using a needle, whether it be solid or cored, we have seen a great deal of tissue trauma that the body responds to by simply scarring over that area. There has not been any patency, either short or long term, when those types of techniques have been used. The laser completely eradicates the tissue. It does not simply push or tear it out of the way, as occurs with the more mechanical devices. I believe the channel stays open because of the laser's precise ability to ablate the tissue and allow the tissue to be eliminated. 